\title{
Optimasi dan Impelementasi Sistem Contactless Tag-Reader untuk Akses Kelas dan Laboratorium : Evaluasi Prototipe
}

\author{
Rida Ariyanti Z*1, Elyas Palantei ${ }^{1}$, Intan Sari Areni ${ }^{1}$ \\ ${ }^{1}$ Jurusan Teknik Elektro, Fakultas Teknik, Universitas Hasanuddin \\ J1. Poros Malino km.6 Bontomarannu, Gowa, Sulawesi Selatan, Indonesia \\ *Email: ${ }^{1}$ ridaariyantizainal@ gmail.com
}

DOI: 10.25042/jpe.052017.09

\begin{abstract}
Abstrak
Smart card contactless yang ada saat ini memiliki jarak jangkau yang terbatas dengan tingkat keamanan yang masih rendah. Oleh karena itu, penelitian ini akan melakukan optimasi pada akses user yang lebih jauh dengan jaminan keamanan yang lebih baik. Penelitian ini akan diimplementasikan pada akses classroom dan laboratory. Hardware yang digunakan terdiri atas smart card dan Raspberry Pi yang berfungsi sebagai server dan card reader yang dapat saling berhubungan dengan mikroprosesor. Pada smart card dan Raspberry tersimpan data user (nomor induk dan nama) yang bisa mengakses kelas atau laboratorium. Data User pada smart card tersimpan di chip yang bertindak seperti RAM (Random Access Memory). Chip tersebut tertanam pada Smart card dengan cara kerja yang sama seperti media penyimpanan. Raspberry yang bertindak sebagai server sekaligus sebagai mikroprosesor akan memberikan akses untuk user yang telah teregistrasi dengan data base server. Penelitian ini menghasilkan sistem akses kelas dengan menggunakan smart card dengan jarak $>5 \mathrm{~cm}$ dengan sistem automatis akses untuk user yang terdaftar pada sistem. Jika menggunakan teori LOS maka maksimal jarak yang dapat dicapai adalah $12 \mathrm{~cm}$. Historical tersimpan pada server yang mencatat waktu in dan out, serta durasi waktu selama berada di ruangan. Teknologi tambahan pada sistem akses classroom ini dilengkapi dengan sistem close door otomatis untuk double security pada classroom. Kelebihan sistem ini adalah menggunakan server sekaligus sebagai mikrokontroller sehingga lebih murah dibandingkan teknologi smart card akses yang tersedia saat ini. Sebagai aplikasi tambahan, sistem ini dilengkapi dengan sistem monitoring jarak jauh sehingga tingkat keamanan ruangan dapat dikendalikan dimanapun dan kapan pun.
\end{abstract}

\begin{abstract}
Optimation and Implementation of Contactless Tag-Reader System for Class and Laboratorium Access: Prototype Evaluation. The existing contactless smart cards have limited coverage with low security levels. Therefore, this research perform optimization on user access further with better security assurance. This research implemented in classroom and laboratory access. Hardware that used consists of Smart cards and Raspberry Pi that serves as a server and card reader that could be interconnected with the microprocessor. On the smart card and Raspberry stored user data (registration number and name) that could access the class or laboratory. User's data on smart cards were stored on chips that used RAM (Random Access Memory). The chip was embedded in the Smart card in the same function as storage media. Raspberry that had function as server and microprocessor that provide access to registered users. This study produced classroom access system by using smart card with distance $>5 \mathrm{~cm}$ with automatic access system for user registered on system. It was according to this research proposed about security and historical data. Historical data stored on the server (Raspberry pi) which records the time in and out, and the duration of time while in the room. Additional technology in the classroom access system is equipped with an automatic door close system for double security in the classroom. The advantages of this system was using server and microcontroller in one package so that it is cheaper than the smart card access technology available today. This sistem has new feature to long distance monitoring for controlling anywhere and everywhere.
\end{abstract}

Kata kunci: Contactless, microcontroller, Raspberry Pi, Reader, Smart card

\section{Pendahuluan}

Smart card merupakan kartu yang memiliki chip sebagai peyimpanan data yang dapat digunakan untuk sistem akses jaringan, menyimpan nilai dan data lainnya [1]. Teknologi smart card didukung oleh kemajuan teknologi komunikasi nirkabel sehingga smart card dapat dibuat menjadi contactless untuk memudahkan user dalam akses atau pengontrolan. Transmisi data terbuka melalui sistem nirkabel menimbulkan tantangan keamanan, yaitu otentikasi dan privasi user [2].

Penelitian sebelumnya tentang contactless smart card yang hanya berfokus pada akses file 
untuk print data dan evaluasi pada tag [3, 4], yang kemudian dikembangkan akses file pada sistem penyimpanan cloud tetapi belum ada jaminan keamanan user [5, 6]. Penelitian kemudian berkembang di tahun 2016 yaitu memastikan keamanan data dengan sistem remote dan menggunakan ID yang dinamis (berubah-ubah) [7] dan remote server memverifikasi legitimasi dari pengguna melalui saluran komunikasi yang terbuka dan tidak aman [8]. Penelitian tersebut sudah terfokus pada otentikasi tetapi belum melakukan sistem akses dengan menggunakan mikrokontroller. Oleh karena itu, penulis melakukan penelitian yang diimplementasikan pada kehidupan sehari-hari dalam bidang akademis, yaitu akses kelas dan laboratorium. Sistem akses kelas dan laboratorium yang menggunakan smart card dengan optimasi pada jarak betujuan untuk memudahkan user dalam akses serta tambahan algoritma keamanan kelas yang tinggi, yaitu pintu tertutup otomatis. Komputer host (dalam penelitian menggunakan Raspberry) dan card reader dapat saling berhubungan dengan mikroprosesor [3].

\section{Penelitian Terkait}

Penelitian dan implementasi smart card telah berkembang dari tahun ke tahun. Sebelumnya telah dilakukan penelitianyang menggunakan contactless dan IC smart card sebagai media untuk otentikasi identitas, menganalisa kondisi dan cara untuk sistem cloud print, dan penelitian teknologi driver key print, enkripsi data, otentikasi identitas ke pusat print oleh Wu Yun [4]. Penelitian lainnya adalah fokus pada smart card dengan interface contactless karena lebih sederhana. Dengan menggunakan Mifare DESFire mampu menemukan beberapa kelemahan dari smart card yang dapat menyebabkan kerentanan jika protokol tersebut tidak dilaksanakan dengan baik. Metode ini dapat digunakan oleh peneliti untuk mengevaluasi keamanan pelaksanaan protokol pada beberapa jenis smart card [5]. Sedangkan untuk metode Unified RB-DAC untuk akses file pada cloud computing menggunakan smart card. RBDAC ini adalah sistem dimana semua user dapat mengakses data yang ditentukan untuk kebutuhan tertentu, tetapi tidak bisa menentukan alokasi data untuk setiap user. Dengan demikian untuk mencapai hal tersebut, ditambahkan ACL untuk semua objek (data) dan ACM untuk semua objek dalam sistem [6]. Penelitian terkait smart card tentang otentikasi pengguna jarak jauh dengan mekanisme dimana server memverifikasi legitimasi dari pengguna melalui saluran komunikasi yang terbuka dan tidak aman. Otentikasi sandi menggunakan smart card telah menjadi salah satu metode yang umum diadopsi untuk melindungi password selama proses transmisioleh Zhengxian Gao, dkk. [7].

Berdasarkan penelitian tersebut maka, penelitian ini merupakan optimasi dari penelitian sebelumnya. Penelitian sebelumnya telah mengalami perkembangan menggunakan smart card dengan reader contactless, namun dengan jarak yang terbatas dan keamanan yang rendah. Pengembangan yang dilakukan adalah menggunakan server sekaligus sebagai mikrokontrollernya. Dalam bidang akademisi, keamanan ruangan kelas atau laboratorium merupakan hal yang sangat penting, sehingga dilakukan pengembangan pada sistem dengan menambahkan aplikasi untuk history user yang menggunakan ruangan, jam masuk, jam keluar serta durasi user berada di dalam ruangan.

\section{Desain Sistem}

Algoritma yang digunakan pada sistem akses ini adalah sebagai berikut:

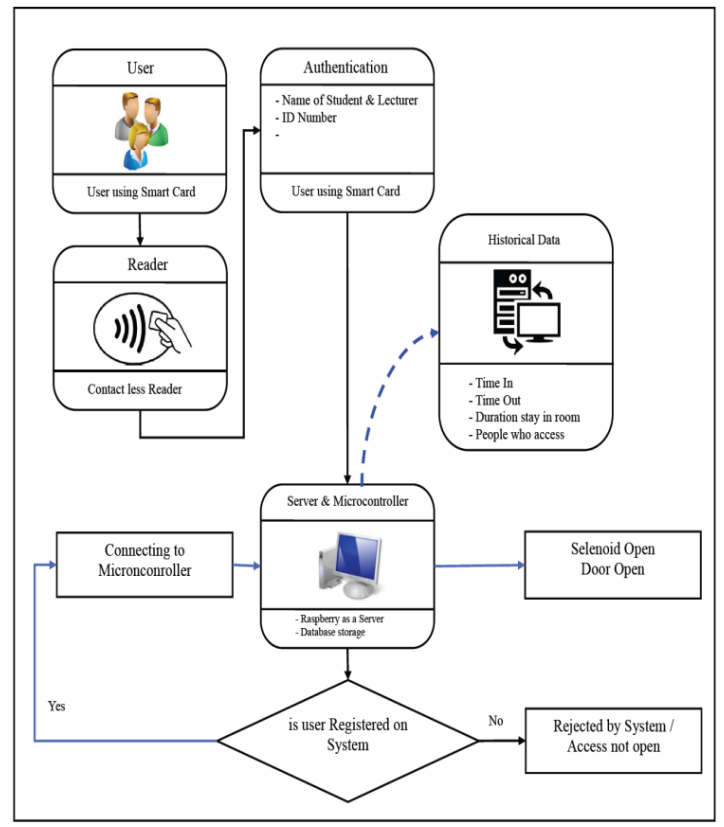

Gambar 1. Algoritma akses kelas dan laboratorium 
Gambar 1 menunjukkan Algoritma pada sistem akses ruangan kelas dan laboratorium. User yang telah terdaftar pada sistem dan tersimpan pada server mengakses dengan cara mendekatkan tag pada reader. Selanjutnya proses otentikasi apakah user tersebut bisa mengakses atau tidak. Sesuai dengan prosedur yang diprogramkan, jika user tidak terdaftar, maka pintu tidak akan terbuka. Sedangkan, jika user tersebut terdaftar, maka pintu yang menggunakan solenoid dan terhubung pada mikrokontroller akan secara otomatis terbuka.

Secara garis besar, sistem ini terdiri atas dua bagian yaitu perancangan sistem dan pengujian sistem.

\subsection{Perancangan Sistem}

Raspberry Pi adalah modul mikro komputer yang juga mempunyai input output digital port seperti mikrokontroller. Kelebihan Rasberry Pi dibanding mikrokontroller yang lain yaitu mempunyai Port/koneksi untuk display berupa TV atau Monitor PC, koneksi USB untuk Keyboard dan Mouse serta memiliki 26 pin I/O digital [8].

Pembuatan sistem akses ruangan memiliki beberapa tahap, yaitu:

- Memasukkan informasi pada smart card (nama, nomor induk mahasiswa / dosen).

- Pemasukan data base pada server yaitu user yang bisa mengakses yang terdiri atas nama dan nomor induk.

- Pemrograman sistem akses dengan detail time in , time out, duration. Sehingga pada saat dilakukan akses data historical bisa muncul pada layar.

Sebagai mikrokontroller, Raspberry dikoneksikan dengan solenoid sehingga pintu secara otomatis bisa terbuka saat proses otentikasi selesai.

Pin GPIO dapat dikonfigurasi sebagai input. Koneksi dari GPIO untuk tegangan yang lebih tinggi dari 3.3V kemungkinan akan menghancurkan blok GPIO dalam SoC [9]. Selain sebagai input output pada beberapa pin GPIO juga berfungsi sebagai komunikasi serial diantaranya I2C, SPI dan serial komunikasi UART [10].

\subsection{Pengujian Sistem}

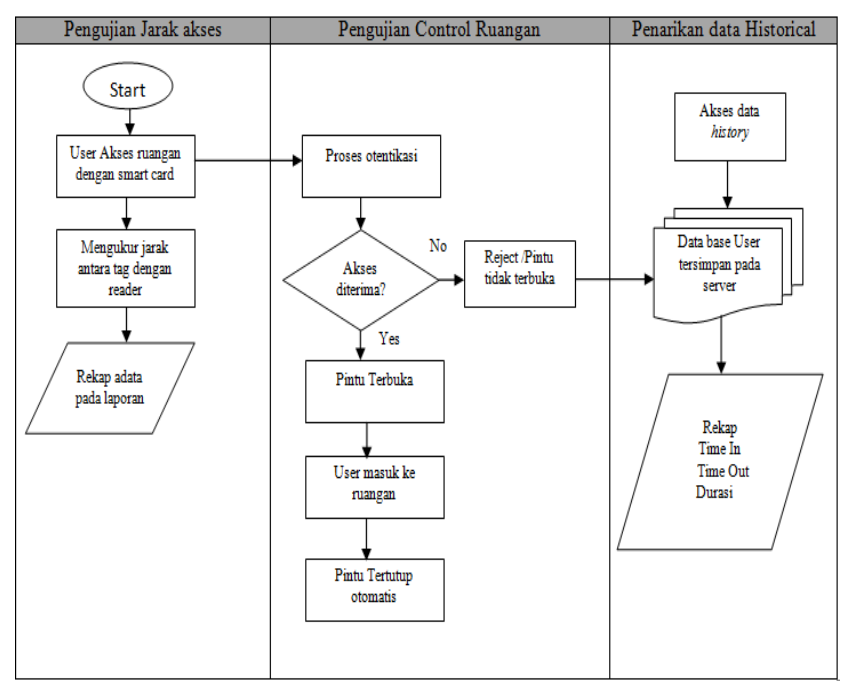

Gambar 2. Diagram pengujian sistem

Gambar 2 menunjukkan suatu uji sistem yang terdiri dari 3 skenario pengujian yang mengukur jarak tag pada pembaca, sistem akses ruangan dimana saat setelah pengguna mengakses ruangan, pintu akan ditutup secara otomatis. Skenario terakhir adalah mengakses data historis yang tersimpan di server. Data berupa waktu, waktu dan durasi pengguna berada di dalam ruangan. Hal ini memungkinkan administrator atau Person bertugas mengawasi ruangan. Keamanan ruangan akan dipastikan dengan fitur tambahan yang otomatis menutup pintu saat pengguna memakan waktu terlalu lama untuk memasuki ruangan.

Hasil pengukuran jarak akan dibandingkan dengan perhitungan Line Of Space atau Line Of Straight (LOS). LOS merupakan garis padang lurus antara 2 titik yang tidak boleh terhalang. Kondisi ini harus dipenuhi untuk memperoleh hasil yang optimal dalam pengiriman sinyal. Pada jarak tertentu tinggi sinyal langsung yang merambat dari pemancar ke penerima dapat dihitung. Selain itu tinggi obstacle maksimum yang dapat menghalangi perambatan sinyal pada tempat tersebut dapat dihitung.

LOS dapat diperoleh melalui persamaan berikut :

$$
X=\sqrt{h_{T x}}+\sqrt{h_{R x}}
$$

Dimana

$\begin{array}{ll}\mathrm{X} & \text { : Jarak LOS } \\ \mathrm{h}_{\mathrm{Tx}} & \text { : Tinggi antena pengirim } \\ \mathrm{h}_{\mathrm{Rx}} & \text { : Tinggi antena penerima }\end{array}$


Disekitar garis lurus (LOS) antar perangkat wireless yang digunakan sebagai area media rambat frekuensi yang disebut juga dengan zona fresnel [11].

\section{Hasil Pengujian Prototipe}

Pengujian yang dilakukan adalah pengujian jarak dan pengujian keamanan ruangan.

\subsection{Hasil Pengujian Jarak}

Dari hasil pengujian diperoleh jarak akses sebagai berikut :

Tabel 1. Rincian data yang direkam oleh sistem smart classroom

\begin{tabular}{cccc}
\hline & \multicolumn{3}{c}{ System Testing Results } \\
\cline { 2 - 4 } $\begin{array}{c}\text { Jarak } \\
(\mathrm{cm})\end{array}$ & Terbaca & Tidak Terbaca & $\begin{array}{c}\text { Pintu Terbuka } \\
\text { (Ya / Tidak) }\end{array}$ \\
\hline 0.5 & $\sqrt{ }$ & - & Ya \\
1 & $\sqrt{ }$ & - & Ya \\
1.5 & $\sqrt{ }$ & - & Ya \\
2 & $\sqrt{ }$ & - & Ya \\
2.5 & $\sqrt{ }$ & - & Ya \\
3 & $\sqrt{ }$ & - & Ya \\
3.5 & $\sqrt{ }$ & - & Ya \\
4 & $\sqrt{ }$ & - & Ya \\
4.5 & $\sqrt{ }$ & - & Ya \\
5 & $\sqrt{ }$ & - & Ya \\
5.5 & $\sqrt{ }$ & - & Ya \\
6 & - & $\sqrt{ }$ & Tidak \\
6.5 & - & $\sqrt{ }$ & Tidak \\
7 & - & & Tidak \\
\hline
\end{tabular}

Pengujian jarak dilakukan dengan cara mendekatkan tag ke reader. Hasil pengujian dapat dilihat pada Tabel 1 yang menunjukkan bahwa jarak maksimum pembacaan reader adalah $5,5 \mathrm{~cm}$. Hal ini menunjukkan sistem yang digunakan telah menggunakan sistem contactlesskarena tidak perlu tag ditapkan atau menempel pada reader.

Jangkauan dari tag yang diukur dari jarak deteksi dengan reader diperoleh bahwa maksimal reader dapat membaca pada jarak $5 \mathrm{~cm}$.

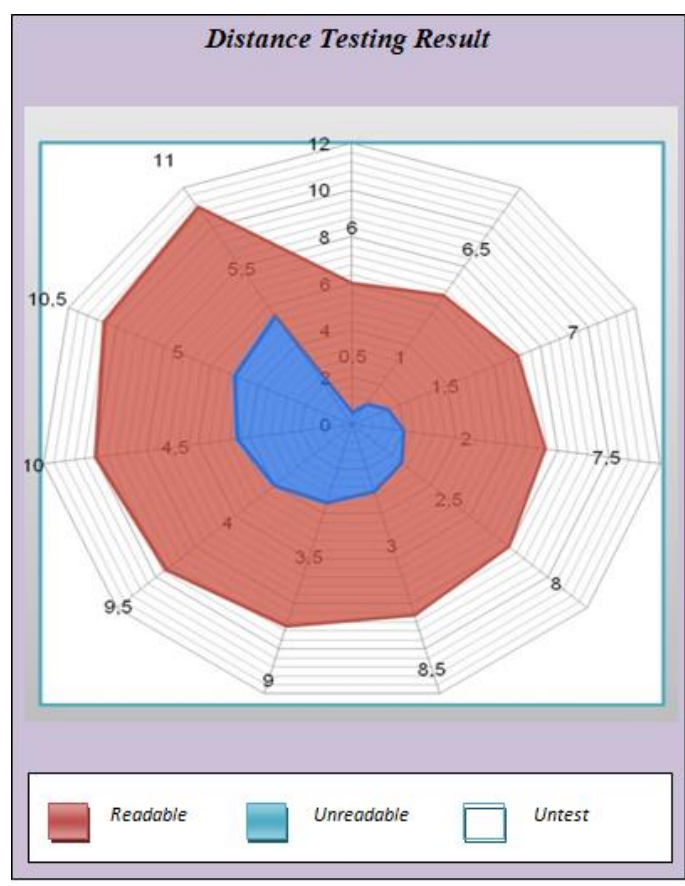

Gambar 3. Jangkauan tag-reader

Gambar 3 menunjukkan bahwa semakin jauh jarak maka kemampuan reader akan semakin berkurang. Garis berwarna biru menunjukkan paling jauh jarak jangkauan reader adalah $5 \mathrm{~cm}$, sedangkan garis berwarna menunjukkan reader sudah tidak membaca tag pada jarak $>5,5 \mathrm{~cm}$ atau pada grafik area yang diberi warna merah. Pengujian dilakukan dari angka $0,5 \mathrm{~cm}$ sampai 7 $\mathrm{cm}$ dengan jarak per $0,5 \mathrm{~cm}$, sedangkan pada jarak $>7 \mathrm{~cm}$ sudah tidak dilakukan pengujian seperti yang ditunjukkan pada gambar area yang berwarna putih.

Pada pengujian smart classroom tinggi reader dipasang sesuai dengan tinggi ideal yang dapat diakses oleh orang. Sehingga, di pastikan di angka $150 \mathrm{~cm}$. Berdasarkan Persamaan 1 dimana $\mathrm{X}$ adalah LOS maka, diperoleh :

$$
\begin{aligned}
& X=\left(\sqrt{h_{T x}}+\sqrt{h_{R x}}\right) \\
& X=(\sqrt{150}+\sqrt{150}) \\
& X=(12,24+12,24) \\
& X=24,48
\end{aligned}
$$

Dari perhitungan LOS diperoleh $24,48 \mathrm{~cm}$. Artinya, area coverage reader adalah $24,48 \mathrm{~cm}$ atau 12,24 $\mathrm{cm}$ dari arah depan dan 12,24 dari arah belakang. 
Tabel 2. Analisa jarak aktual dan berdasarkan perhitungan LOS

\begin{tabular}{ccc}
\hline Percobaan & $\begin{array}{c}\text { Jarak } \\
(\mathbf{c m})\end{array}$ & $\begin{array}{c}\text { Teori LOS } \\
(\mathbf{c m})\end{array}$ \\
\hline 1 & 0,5 & 24,5153 \\
2 & 1,0 & 24,5357 \\
3 & 1,5 & 24,5560 \\
4 & 2,0 & 24,5763 \\
5 & 2,5 & 24,5965 \\
6 & 3,0 & 24,6168 \\
7 & 3,5 & 24,6370 \\
8 & 4,0 & 24,6571 \\
9 & 4,5 & 24,6773 \\
10 & 5,0 & 24,6973 \\
11 & 5,5 & 24,7174 \\
12 & 6,0 & 24,7374 \\
13 & 6,5 & 24,7574 \\
14 & 7,0 & 24,7774 \\
\hline
\end{tabular}

Tabel 2 memperlihatkan bahwa jarak paling dekat antara tag dan reader adalah $0.5 \mathrm{~cm}$ sedangkan jarak terjauh adalah $5.5 \mathrm{~cm}$. Dari hasil percobaan tersebut dapat dilihat perbandingan jarak aktual dan perhitungan teori LOS pada Gambar berikut :

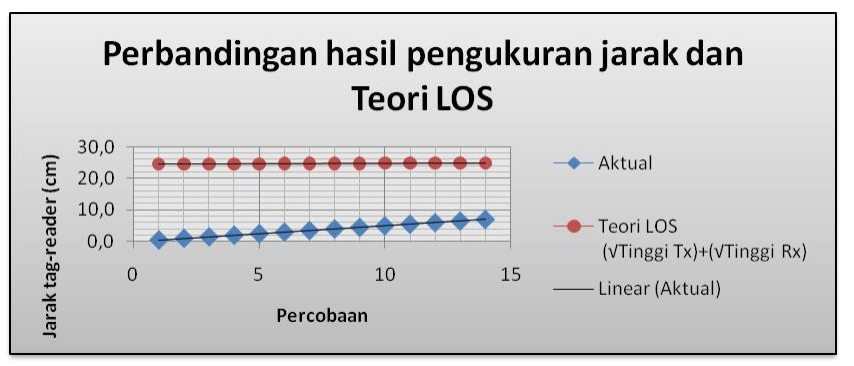

Gambar 4. Grafik perbandingan hasil pengukuran aktual dan secara teori LOS

Pada Gambar 4 terlihat hasil pengukuran yang diambil sesuai dengan Tabel 3. Pengambilan data dilakukan dengan perbedaan jarak $0,5 \mathrm{~cm}$. Dilakukan sebanyak 14 kali hingga tag dan readerberada pada jarak $7 \mathrm{~cm}$. Berdasarkan perhitungan secara teori LOS, jarak yang bisa dicapai adalah 12,24 $\mathrm{cm}$ namun aktual maksimal yang bisa dideteksi reader adalah $5,5 \mathrm{~cm}$.

\subsection{Pengujian Solenoid}

Pengujian pada solenoid door lock dilakuan pada tag yang telah terdaftar dan belum terdaftar pada database.

Solenoid berfungsi dengan baik dengan membuka lock solenoid saat tag yang terdaftar didedaktkan pada reader baik saat check in maupun check out dari kelas. Penujian dilakukan pada tag yang tidak terdaftar dan yang terdaftar. Terbukti bahwa user yang tidak terdaftar akan tetap terekam pada sistem dengan nama "unregistered card".

Tabel 3. Rincian tampilan user tidak terdaftar

\begin{tabular}{ccl}
\hline Percobaan & No. Kartu & Tanggal/Waktu \\
\hline 1 & $115-12-9-1$ & $29-07-2017 / 08: 06: 46$ \\
2 & $194-199-245-252$ & $29-07-2017 / 08: 07: 25$ \\
3 & $34-45-15-253$ & $29-07-2017 / 08: 08: 11$ \\
\hline
\end{tabular}

Tabel 3 memperlihatkan sistem akan menunjukkan berapa kartu yang tidak terdaftar yang mengakses ruangan dan frekuensi user mencoba mengakses ruangan.

\subsection{Pengujian Durasi}

Hasil pengujian ditampilkan dalam format berupa (jam : menit : detik). Pengukuran durasi dapat dilihat pada persamaan berikut :

Durasi $=$ Waktu keluar - Waktu masuk

Pengujian ini dilakukan pada salah satu kartu atas nama Enal Roffca dimana pada pengujian pertama saat masuk pada pukul 06:16:34 dan keluar pada pukul 06:17:19. Berdasarkan Persamaan 2 selisih waktu pada pengujian adalah 45 detik. Hal ini menunjukkan bahwa rekaman durasi detail sampai pada detik.

Tabel waktu yang tecatat adalah tabel waktu masuk, waktu keluar, dan durasi waktu. Pada pengaturan awal, semua tabel kosong. Dan saat user melakukan scan untuk masuk maka tabel waktu masuk akan di update dengan waktu pada sistem raspberry saat user melakukan scan.

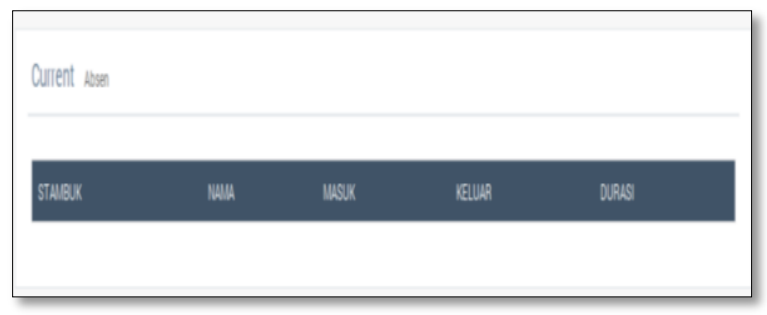

Gambar 5. Tampilan awal absen

Seperti pada Gambar 5, tampilan sistem masih dalam keadaan tidak ada user yang mengakses. Saat user melakukancheck in, maka 
akan muncul rekapan absen seperti pada Gambar 6.

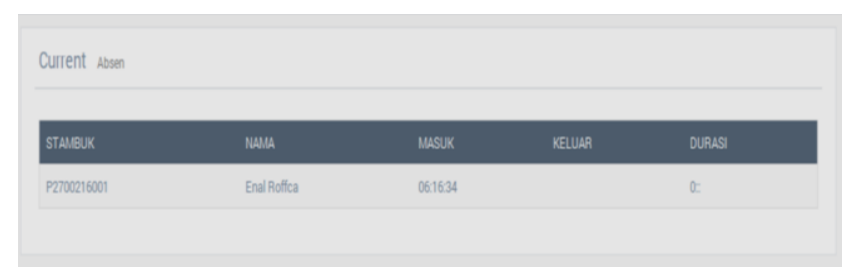

Gambar 6. User check in

Pada Gambar 6 user melakukan check in pada pukul 06:16:34 namun belum melakukan check out. Artinya, selama waktu tersebut user masih berada di dalam ruangan. Pada tabel durasi waktu masih 0 karena waktu check out masih belum terekam dalam sistem. Saat melakukan check out sistem akan mendeteksi waktu check out dan secara otomatis akan muncul durasi berada di ruangan dan tabel durasi akan di update sesuai dengan waktu check out. Selisih waktu akan otomatis dihitung ketika waktu masuk dan waktu keluar terisi dan tercatat sebagai durasi.

\section{Kesimpulan}

Dari hasil penelitian dan analisa yang telah dilakukan, disimpulkan bahwa pembuatan prototipe dan pengujian sistem smart classroom maksimal jarak tag ke reader terdekat $0,5 \mathrm{~cm}$ dan terjauh 5,5 $\mathrm{cm}$. Jika dibandingkan dengan perhitungan secara teori LOS jarak terdekat 12,2 $\mathrm{cm}$ dan jarak terjauh adalah $12,3 \mathrm{~cm}$. Percobaan prototype dengan menggunakan solenoid menunjukkan bahwa saat user yang terdaftar mengakses masuk dan keluar maka solenoid secara otomatis terbuka dan tercatat pada sistem, sedangkan user yang tidak terdaftar pada sistem mengakses maka solenoid tidak akan terbuka dan akan tercatat pada sistem. Percobaan sistem keamanan dengan menggunakan 3 kartu yang tidak terdaftar tercatat detail waktu dan nomor kartu nomor yang mencoba mengakses ruangan, tetapi ditolak oleh sistem dan tercatat.

\section{Ucapan Terimakasih}

Penelitian ini dibantu oleh anggota Komunitas Cyber Tech Jurusan Elektro Universitas Hasanuddin.

\section{Referensi}

[1] M. Wassim Raad, Tarek Sheltami ,M. Sallout, "A Smart card Based Prepaid Electricity System", IEEE [Pervasive Computing and Applications, 2007. ICPCA 2007. 2nd International Conference].

[2] Alavalapati Goutham Reddy, Eun-Jun Yoon, Ashok Kumar Das, Kee Young Yoo, "Lightweight Authentication With Keyagreement Protocol For Mobile Network Environment Using Smart Cards", IEEE [The Institution of Engineering and Technology 2016].

[3] Agnes C. Noubissi, Julien Iguchi-Cartigny, Jean-Louis Lanet, "Hot Updates for Java Based Smart cards",IEEE, 2011 [ICDE Workshops].

[4] Wu Yun, "Research of Cloud Print Key Technology Base on Identity “. IEEE, 2012 [Third World Congress on Software Engineering].

[5] Matej Kacic, Petr Hanacek, Martin Henzl, Ivan Homoliak, "A concept of behavioral reputation system in wireless networks", IEEE, 2013 47th International Carnahan Conference on Security Technology (ICCST).

[6] B. Linkesh, S.Durga, E. Chowdary, Unified RB-DAC Approach With Secure Authentication Using Smart card Architecture, IEEE [2014 3rd International Conference on Eco-friendly Computing and Communication Systems].

[7] Shanu Gaharana, Darpan Anand, "Dynamic ID Based Remote User Authentication In Multi Server Environment Using Smart cards: A Review", IEEE, 2015, International Conference on Computational Intelligence and Communication Networks (CICN).

[8] Zhengxian Gao, Shou Hsuan Stephen Huang, Wei Ding, "Cryptanalysis of Three Dynamic ID-Based Remote User Authentication Schemes Using Smart cards", 2016, IEEE International Conference of Online Analysis and Computing Science (ICOACS).

[9] Qihao He; Bruce Segee; Vincent Weaver, "Raspberry Pi 2 B+ GPU Power, Performance, and Energy Implications", IEEE, 2016 International Conference on Computational Science and Computational.

[10] Vamsikrishna Patchava, Hari Babu Kandala, P Ravi Babu, "A Smart Home Automation technique with Raspberry Pi using IoT", IEEE, 2015, International Conference on Smart Sensors and Systems (IC-SSS).

[11] Muhadir. Rancang Bangun Sistem Identifikasi Kendaraan Pada Akses Masuk Menggunakan Teknologi RFID. 2008. Depok: Departemen Teknik Elektro Fakultas Teknik, Universitas Indonesia. 